\title{
RESTRUKTURISASI BERPIKIR SISWA MELALUI PEMUNCULAN SKEMA DALAM MENYELESAIKAN SOAL UJIAN NASIONAL MATA PELAJARAN MATEMATIKA
}

\author{
Siti Aisya ${ }^{1}$, Kusaeri ${ }^{2}$, Sutini $^{3}$ \\ ${ }^{1,2,3}$ UIN Sunan Ampel Surabaya \\ Corresponding author: sitiaisya35@gmail.com ${ }^{1}$
}

\begin{abstract}
Restructuring student's thinking can be called defragmentation of student's thinking structures. Defragmentation of student's thinking structures through scheme appearance to fix pseudo thinking student's in solving problems HOTS test type for mathematics in the National Exam 2018. Pseudo Thinking happened because students did not reflect before answering, so students give the wrong answer. Pseudo thinking divided into false-pseudo thinking and true-pseudo-thinking. Hence, in this research to describe student's structural thinking errors and the process of defragmentation of student's thinking structures through scheme appearance to fix student's pseudo thinking in solving problems of HOTS test type for mathematics in the National Exam 2018. This research is qualitative research with a descriptive type. Researchers used three subjects to describe the defragmentation process of scheme appearance. The result of this research, all subjects experienced false-pseudo thinking and true-pseudo thinking. From the research, subjects can reveal that the process of scheme appearance that has been previously. So, subjects can solve problems.
\end{abstract}

Keywords: Pseudo; Defragmentation of scheme appearance; National exam; Thinking structures

How to cite: Aisya, S., Kusaeri \& Sutini. (2019). Restrukturisasi Berpikir Siswa Melalui Pemunculan Skema dalam Menyelesaikan Soal Ujian Nasional Mata Pelajaran Matematika. JRPM (Jurnal Review Pembelajaran Matematika), 4(2), 157-165.

\section{PENDAHULUAN}

Berdasarkan laporan hasil UN, nilai matematika siswa SMP mengalami penurunan tiap tahunnya. Nilai rata-rata UN Matematika pada setiap jenjang, salah satunya jenjang SMP selalu berada di bawah 6,00 selama tiga tahun terakhir ini (Sumaryanta, Priatna, \& Sugiman, 2019). Hal ini juga terlihat dari perbandingan hasil UN tahun 2018 dengan tahun sebelumnya. Pada tahun 2017, nilai matematika siswa SMP dalam UN yaitu 48,63. Nilai ini turun menjadi 44,38 pada tahun 2018 (Data Laporan Hasil UN Matematika SMP/MTs). Salah satu faktor yang menyebabkan turunnya rata-rata nilai UN dikarenakan kesulitan siswa dalam menyelesaikan UN. Siswa menganggap soal-soal UN terlalu sulit. Kesulitan tersebut dapat disebabkan karena siswa kurang memahami objek dan pelajaran matematika itu sendiri (Wasida \& Hartono, 2018). Namun pada kenyatannya, soal-soal dalam UN tidak sesulit yang mereka keluhkan. Hanya saja siswa belum terbiasa dalam menyelesaikan soal yang serupa (Kusaeri, Hamdani, \& Suprananto; 2019).

Adanya penambahan soal berjenis HOTS juga membuat siswa merasa kesulitan dalam 
menjawab soal UN. Akibat dari kurang pahamnya siswa terhadap soal HOTS dapat menimbulkan kebingungan dalam menemukan jawaban yang benar (Kamarullah, 2017). Kesalahan dalam pengerjaan soal HOTS dapat terjadi karena adanya kelemahan dalam proses pembelajaran. Pada umumnya dalam proses pembelajaran matematika, yang menjadi tujuan dari pembelajaran adalah cara memperoleh jawaban dan prosedurnya saja. Sehingga ketika melakukan penyelesaian soal, siswa hanya meniru apa yang telah diajarkan sebelumnya. Sebaiknya, pemberian kesempatan kepada siswa untuk memahami konsep dalam pembelajaran matematika juga perlu diperhatikan, bukan hanya melatih siswa untuk menerapkan rumus dan prosedur yang ada (Kusaeri \& Anindito, 2019).

Wibawa mengatakan, kecenderungan siswa untuk memilih prosedur penyelesaian soal tanpa mengetahui alasannya dapat mengakibatkan ia mengalami berpikir pseudo atau berpikir semu (Wibawa, Nusantara, Subanji, \& Parta, 2018). Terkadang siswa hanya melihat kemiripan dari soal. Jika soal yang dikerjakan dirasa mirip dengan soal yang pernah dikerjakan sebelumnya, maka proses penyelesaian cepat dilakukan. Sebaliknya, jika telah dilakukan perubahan dari soal sebelumnya, maka ia mengalami kesulitan. Masalah seperti inilah juga termasuk kedalam pseudo (Subanji, 2013a).

Wibawa dkk (2016) menjelaskan bahwa berpikir pseudo atau berpikir semu yaitu ketika siswa dapat memberikan jawaban yang benar namun belum tentu dihasilkan dari proses berpikir yang benar dan jawaban salah yang dihasilkan belum tentu bersumber dari pikiran yang salah. Berpikir $p$ seudo bukanlah hasil dari proses berpikir sesungguhnya tetapi dari proses berpikir semu. Karena keterpaksaan yang dilakukan siswa dalam mempelajari topik-topik serta tidak dilakukannya kontrol terhadap apa yang dipikirkannya ketika memecahkan masalah (Santoso, 2017). Subanji (2013a) dalam penelitiannya juga mengelompokkan berpikir pseudo berdasarkan kepada hasil akhir yang siswa berikan serta proses klarifikasinya, dapat dibedakan pula menjadi dua kelompok, yaitu: berpikir pseudo benar dan berpikir psendo salah.

Siswa yang dapat menyelesaikan masalah matematika dan memperoleh hasil akhir yang benar, namun tidak dapat memberikan alasan dari hasil akhirnya. Maka hasil akhir yang diberikan adalah semu dan siswa mengalami berpikir pseudo benar. Namun, jika siswa yang memberikan hasil akhir yang salah tersebut setelah dilakukan pengecekan dapat memberikan hasil akhir yang benar dari proses perbaikan, maka siswa mengalami berpikir pseudo salah (Wibawa dkk, 2016; Subanji; 2013a)

Penelitian tentang kesalahan siswa dalam menyelesaikan soal HOTS telah dikaji pada penelitian-penelitian sebelumnya, salah satunya adalah Wilda Mahmudah (Mahmudah, 2018). 
Namun penelitian tersebut belum sampai mengkaji penemuan sumber kesalahan melalui pengungkapan proses berpikir siswa dalam menyelesaikan soal HOTS serta cara mendefragmentingnya. Hidayanto dan Subanji (2017) menyatakan bahwa defragmenting struktur berpikir adalah penataan ulang struktur berpikir ketika melakukan kesalahan dalam menyelesaikan permasalahan matematika melalui proses scaffolding, conflict cognitive, dan disequilibrasi. Defragmenting yang digunakan untuk mengatasi berpikir pseudo adalah tipe pemunculan skema.

Proses defragmenting struktur berpikir yang diberikan kepada siswa akan dilakukan dengan bantuan dari orang lain. Bantuan yang diberikan berupa conflict cognitive, scaffolding serta disequilibrasi. Pemberian bantuan melalui conflict cognitive dengan memberikan pertanyaanpertanyaan yang menimbulkan konflik dalam pikirannya, sehingga membuat siswa akan berpikir ulang tentang jawaban yang diberikan (Kumalasari, Nusantara, Sa'dijah; 2016). Adanya disequilibrasi akan mempermudah intervensi melalui scaffolding. Keraguan yang dialami oleh siswa merupakan dasar untuk memberikan bantuan untuk perubahan struktur berpikirnya. Scaffolding dilakukan dengan memberikan bantuan secukupnya, dan secara perlahan bantuan tersebut akan berkurang jika siswa dapat mengkontruksi ataupun menyelesaikan masalah dengan benar (Subanji, 2013b).

\section{METODE PENELITIAN}

Penelitian ini merupakan jenis peneitian deskriptif kualitatif yang akan mendeskripsikan proses defragmenting struktur berpikir siswa dalam memecahkan soal UN Matematika berbasis HOTS yang mengalami kesalahan berpikir pseudo. Pelaksanaan penelitian dilaksanakan pada semester Gasal tahun ajaran 2019/2020 di SMPN 55 Surabaya. Penelitian dilakukan kepada 3 siswa dari 30 siswa SMPN 55 Surabaya yang memenuhi kriteria sebagai subjek penelitian, yaitu 3 siswa yang mengalami berpikir pseudo sesuai dengan indikator berpikir psendo ketika menyelesaikan masalah UN Matematika. Teknik pengumpulan data yang digunakan berupa tes tulis dan wawancara. Tes tulis menggunakan instrumen lembar soal tes tulis. wawancara menggunakan instrumen berupa pedoman wawancara. Data hasil tes tulis dianalisis untuk mengetahui proses berpikir pseudo ketika mengerjakan UN Matematika berbasis HOTS. Data hasil wawancara digunakan untuk mengetahui lebih dalam proses berpikir pseudo serta proses defragmenting yang dilakukan. 


\section{HASIL DAN PEMBAHASAN}

Penelitian ini menggunakan 3 subjek dari kelas VIII yang mengalami berpikir pseudo dalam mengerjakan UN Matematika berbasis HOTS tahun 2018.

\section{Kesalahan Struktur Berpikir Siswa dalam Menyelesaikan UN Matematika Berbasis HOTS}

Kesalahan struktur berpikir yang dialami semua subjek yaitu pseudo benar dan pseudo salah. Salah satu faktor dominan yang membuat subjek mengalami pseudo karena kurang memahami soal. Sejalan dengan pernyataan Wibawa yang menyatakan bahwa, proses berpikir pseudo diawali dengan kesalahan dalam memahami soal (Wibawa, Nusantara, Subanji, Parta; 2018). Jika dilihat dari tipe soal UN yang diberikan, yaitu soal berbentuk cerita. Berdasarkan penelitian yang dilakukan oleh Hanifah, siswa masih mengalami kendala dalam memahami soal berbentuk cerita (Hanifah, 2009).

Berdasarkan indikator faktor-faktor penyebab berpikir pseudo, terlihat bahwa subjek mengalami berpikir pseudo dikarenakan kurangnya pemahaman terhadap materi prasyarat. Kurangnya pemahaman subjek terhadap materi prasyarat dapat disebabkan karena skema yang dimiliki subjek untuk menyelesaikan masalah belum teraktivasi dengan baik. Berikut cuplikan wawancara yang menunjukkan kurangnya pemahaman terhadap materi prasyarat:

P : Boleh dijelaskan kenapa menggunakan kata- kata dalam menuliskan apa yang diketahui?

$\mathrm{S} \quad$ : Soalnya saya pahamnya pakai yang kata-kata aja kak.

$\mathrm{P}-\mathrm{X}_{1}$ : Kalau materi tentang irisan dan gabungan dalam himpunan masih ingat tidak?

$\mathrm{S}_{1}-\mathrm{X}_{1}$ : Sudah agak lupa kak.

Jika dilihat dari cuplikan wawancara di atas, subjek kurang memahami materi prasyarat yang dibutuhkan dalam mengerjakan soal yaitu materi gabungan, komplemen dan juga irisan.

Setelah kurangnya pemahaman terhadap materi prasyarat, faktor lain yang dapat menyebabkan berpikir pseudo yaitu hilangnya tahap kontrol. Hilangnya tahap kontrol yang dialami oleh subjek, ditandai dengan terburu-burunya dalam merespon dan tidak melakukan pengecekan kembali terhadap respon yang dilakukan, contohnya tidak melakukan pengecekan kembali terhadap jawaban yang diberikan dan mengabaikan salah satu komponen yang harus diketahui pada informasi. Berikut cuplikan wawancara yang menunjukkan hilangnya tahap kontrol:

P : Boleh dijelaskan kembali proses perhitungannya 


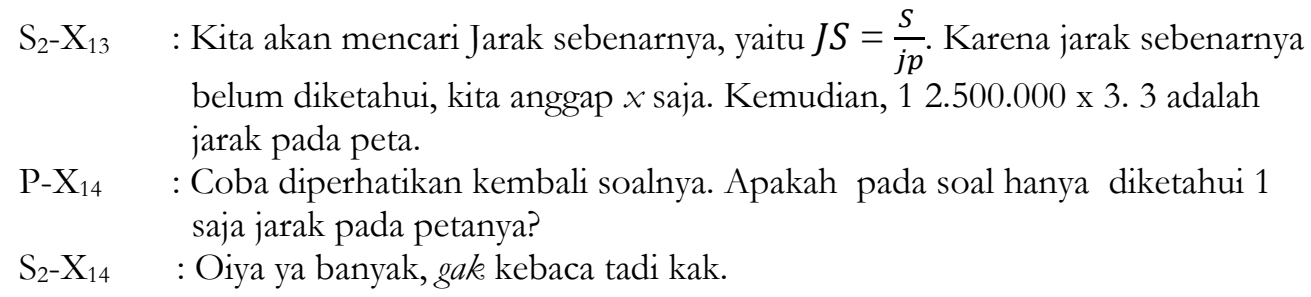

Berdasarkan cuplikan wawancara tersebut, subjek kehilangan tahap kontrol karena terburu-buru dalam melakukan perhitungan. Selain itu, ia melewatkan informasi lain yang digunakan dalam menyelesaikan soal.

Faktor kebiasaan juga menjadi penyebab subjek mengalami berpikir pseudo. Pada umumnya, subjek akan memilih prosedur penyelesaian yang biasa digunakan ketika menyelesaikan suatu masalah tanpa mengetahui alasan menggunakan prosedur tersebut. Dalam penelitian ini, proses penyelesaian soal yang dilakukan oleh subjek karena terbiasa menggunakan aturan "pindah ruas" dan penjumlahan bentuk aljabar. Berikut cuplikan wawancaranya:

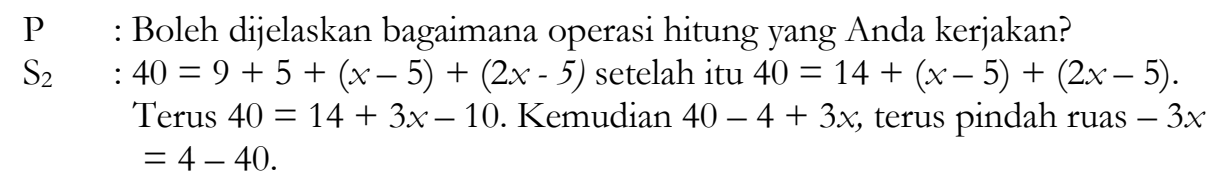

Kesalahan struktur berpikir subjek terlihat ketika menggunakan aturan pindah ruas. Subjek sudah terbiasa melakukan pindah ruas untuk memudahkan ia menemukan nilai dari $x$. Kemudian saat melakukan operasi penjumlahan dalam bentuk aljabar. Subjek mengkonstruksi konsep penjumlahan bentuk aljabar dengan huruf yang sama atau seletak. Konsep tersebut diperoleh subjek ketika melakukan pembelajaran di kelas.

P : Kenapa Anda menjumlahkan $x$ dengan $2 x$, kenapa bukan $x-5$ ?

$\mathrm{S}_{2} \quad$ : Soalnya $x-5$ tidak bisa dioperasikan

$\mathrm{P} \quad$ : Kenapa tidak bisa dioperasikan?

$\mathrm{S}_{2}-\mathrm{X}_{9} \quad$ : Karena tidak sama hurufnya kak. Kita harus menjumlahkan dengan huruf atau angka yang sama atau seletak. Misalkan $x$ dengan $2 x$ karena ada huruf yang sama.

$\mathrm{P} \quad$ : Apakah menurut Anda sudah benar pengoperasiannya?

$\mathrm{S}_{2} \quad$ : Iya kak.

Faktor terakhir yang dapat menyebabkan subjek berpikir pseudo adalah belajar hafalan. Subjek menghafal rumus yang baru saja diperolehnya yaitu rumus mencari jarak sebenarnya tanpa mengaitkan dengan konsep yang dimiliki sebelumnya. Yaitu rumus skala yang sudah ada dalam struktur kognitifnya.

\section{Defragmenting Struktur Berpikir Siswa melalui Pemunculan Skema dalam}

\section{Menyelesaikan UN Matematika Berbasis HOTS}

Kesalahan struktur berpikir yang dialami subjek terjadi karena skema-skema berpikir yang dimiliki subjek untuk menyelesaikan soal belum muncul dan tidak dapat 
terkoneksikan dengan baik. Peneliti akan memberikan intervensi terbatas yang bertujuan agar subjek dapat menyadari kesalahan yang dilakukan dan memunculkan skema yang diperlukan. Sehingga perlu adanya perbaikan melalui scaffolding, conflict cognitive, dan disequilibrasi. Setelah subjek mendapatkan intervensi terbatas, maka akan terjadi penstrukturan ulang terhadap struktur berpikir subjek dengan menambahkan skema baru yang baru saja muncul agar dapat terkoneksikan menjadi skema yang utuh.

Pemberian bantuan dengan scaffolding dilakukan dengan memberikan bantuan berupa pertanyaan, petunjuk, maupun arahan kepada subjek agar struktur berpikirnya tertata dengan baik dan memunculkan skema yang dibutuhkan dalam menyelesaikan soal. Berikut scaffolding yang diberikan kepada subjek untuk

$\mathrm{P}-\mathrm{X}_{1}$ : Kalau materi tentang irisan dan gabungan dalam himpunan masih ingat tidak?

$\mathrm{S}_{1}-\mathrm{X}_{1}$ : Sudah agak lupa kak.

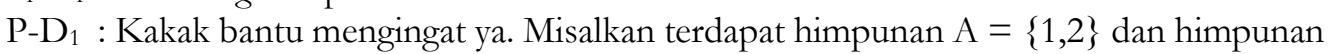
$\mathrm{B}=\{1,2,3\}$. Manakah anggota yang dimiliki himpunan $\mathrm{A}$ dan juga himpunan $\mathrm{B}$ ? (Scaffolding)

$\mathrm{S}_{1} \quad: 1$ dan $2 \mathrm{kak}$

$\mathrm{P} \quad$ : Oke betul. $\mathrm{A} \cap \mathrm{B}=\{1,2\}$. Jadi irisan adalah?

$\mathrm{S}_{1} \quad$ : Anggota yang sama atau dimiliki oleh kedua himpunan.

$\mathrm{P} \quad$ : Kalau begitu, manakah yang menunjukkan irisan dalam soal?

$\mathrm{S}_{1}-\mathrm{D}_{1}$ : (Berpikir sejenak) Yang dimiliki keudanya ya kak? Yang suka kedua-duanya, berarti pembaca yang menyukai majalah politik dan olahraga.

$\mathrm{P} \quad$ : Betul, tolong dituliskan bagaimana?

$\mathrm{S}_{1} \quad: \mathrm{X} \cap \mathrm{Y}=5$

$\mathrm{P} \quad$ : Betul. Kemudian untuk informasi "tidak menyukai keduanya", bagaimana?

$\mathrm{S}_{1} \quad$ : Seingat saya kalau bukan anggota himpunan itu komplemen kak.

P : Kalau dari informasi soal, "tidak menyukai keduanya" itu maksudnya tidak menyukai apa?

$\mathrm{S}_{1} \quad$ : Tidak menyukai majalah politik dan olahraga.

Proses scaffolding yang dilakukan diatas bertujuan untuk memunculkan skema subjek tentang materi komplemen. Dalam penelitian ini, selain bertujuan untuk memunculkan skema tentang materi prasyarat himpunan, juga bertujuan untuk mengarahkan struktur berpikir siswa yang salah tentang konsep pindah ruas menjadi struktur berpikir yang benar, dan arahan-arahan lain yang membantu subjek memperbaiki kesalahannya.

Disequilibrasi diberikan kepada subjek melalui pertanyaan-pertanyaan yang menimbulkan kesenjangan dalam pikiran sehingga subjek akan melakukan refleksi terhadap jawabannya, Disequilibrasi yang diberikan dalam penelitian ini bertujuan untuk menyadarkan subjek tentang kebiasaannya melakukan "pindah ruas" dan menyadarkan subjek tentang kekeliruannya terhadap konsep operasi aljabar. Contoh 
disequilibrasi yang dilakukan untuk menyadarkan kesalahan perhitungan "pindah ruas" berikut:

P-X $\mathrm{X}_{4}$ : Apakah Anda bisa yakin dengan proses perhitungan yang dilakukan?

S1-X: Iya kak yakin. Biasanya kalau mengerjakan seperti itu. Tadi juga tanya dulu caranya seperti apa.

P : Berarti tadi tanya dulu ya cara mengerjakannya seperti apa?

$\mathrm{S}_{1} \quad$ : Iya kak, jadi saya langsung kerjakan saja seperti itu.

$\mathrm{PD}_{4}$ : Pada proses perhitungan $40=14+3 x$, kemudian dengan pindah ruas menjadi $40-14=3 x$, seandainya saya menghitungnya dengan kedua ruas dikurangi 14 bagaimana?

$S_{1} \quad: 40-14=14-14+3 x$. seperti ini kak?

$\mathrm{P} \quad$ : Betul, jadi hasilnya berapa?

$\mathrm{S}_{1}-\mathrm{D}_{4}: 40-14=3 x$. Oh iya sama kak. Jadi tidak perlu pindah ruas.

Berdasarkan hasil wawancara di atas, tampak subjek dapat memperbaiki struktur berpikirnya, setelah dilakukan proses disequilibrasi. Terbukti ketika siswa mengatakan "Jadi tidak perlu pindah ruas", berarti struktur berpikir subjek tersebut telah terdefragmenting. Sehingga subjek dapat melakukan penyelesaian dengan baik.

Kemudian, conlict cognitive yang diberikan dalam penelitian dengan memberikan contoh lain yang membuat subjek berpikir ulang terhadap jawaban yang dilakukan. Pemberian conflict cognitive kepada subjek salah satunya untuk menyadarkan subjek terhadap kesalahan operasi bentuk aljabar yang dilakukan.

P : Boleh dijelaskan bagaimana operasi hitung yang Anda kerjakan?

$\mathrm{S}_{2} \quad: 40=9+5+(x-5)+(2 x-5)$ setelah itu $40=14+(x-5)+(2 x-5)$. Terus 40 $=14+3 x-10$. Kemudian $40=4+3 x$, terus pindah ruas $-3 x=4-40$.

$\mathrm{P}-\mathrm{X}_{10}:$ Apakah Anda yakin dengan cara tersebut?

$\mathrm{S}_{2}-\mathrm{X}_{10}$ : Yakin. Kan mau dicari $x$ nya.

$\mathrm{P}_{\mathrm{D} 10}$ : Seandainya saya menghitungnya dengan kedua ruas dikurangi 4 bagaimana? (Disequilibrasi dan Scaffolding)

$\mathrm{S}_{2} \quad$ : Hmm. Jadi $4-4+(-3 x)=4-40$ Begini?

$\mathrm{P} \quad$ : Betul, jadi hasilnya berapa?

$\mathrm{S}_{2 \text {-D10 }}:-3 x=-36$. Oh begitu.

P : Coba diperiksa kembali jawaban akhirnya, apakah Anda sudah menyelesaikan sampai akhir?

$\mathrm{S}_{2} \quad$ : Iya kak. Sudah ketemu $x=12$

$\mathrm{P}_{\mathrm{D} 11} \quad$ : Kalau begitu, apakah $x=12$ itu berarti orang yang menyukai majalah olahraga?

$\mathrm{S}_{2-\mathrm{D} 11}$ : Oiya bukan kak. Jadi, banyaknya pembaca yang menyukai majalah politik adalah 12 orang.

Berdasarkan bantuan-bantuan yang dilakukan oleh peneliti berupa scaffolding, conflict cognitive, dan disequilibrasi dapat mengurangi kesalahan yang dilakukan oleh subjek. Selain itu, skema-skema yang belum muncul sebelumnya dapat muncul kembali dan membantu subjek menyelesaikan masalah. 


\section{SIMPULAN DAN SARAN}

Kesalahan struktur berpikir yang dialami semua subjek adalah berpikir pseudo benar dan berpikir pseudo salah. Dimana pseudo benar dikarenakan subjek memberikan jawaban seolaholah benar, namun sebenarnya tidak sesuai dengan konsep matematika karena diperoleh dari hasil berpikir yang kurang tepat. Sedangkan subjek yang mengalami pseudo salah disebabkan jawaban yang diberikan seolah-olah salah, namun pada dasarnya subjek dapat memperbaiki jawabannya secara benar sesudah dilakukan defragmenting. Kesalahan tersebut disebabkan karena faktor kurang memahami materi prasyarat, hilangnya tahap kontrol, faktor kebiasaan, dan menyukai belajar hafalan.

Proses defragmenting melalui pemunculan skema diberikan untuk memperbaiki kesalahan berpikir pseudo. Perbaikan dilakukan dengan pemberian bantuan terbatas melalui scaffolding, conflict cognitive, dan disequilibrasi. Proses defragmenting melalui scaffolding bertujuan untuk memunculkan skema yang akan digunakan dan mengarahkan struktur berpikir subjek yang masih salah.

Oleh karena itu, peneliti selanjutnya dapat mempertimbangkan faktor-faktor lain seperti gaya belajar siswa dan gaya kognitif sehingga dapat melihat kesalahan struktur berpikir siswa serta proses defragmenting yang dilakukan melalui karakter subyek yang berbeda.

\section{DAFTAR RUJUKAN}

Hanifah, E. H. (2009). Identifikasi Kesalahan Siswa SMP dalam Menyelesaikan Soal Cerita Matematika Materi SPLDV Berdasarkan Metode Analisis Kesalahan Newman. Surabaya: IAIN Sunan Ampel Surabaya.

Hidayanto, T., Subanji, Hidayanto, E. (2017). Deskripsi Kesalahan Struktur Berpikir Siswa SMP dalam Menyelesaikan Masalah Geometri Serta Defragmentingnya: Suatu Studi Kasus. Jurnal Kajian Pembelajaran Matematika. 1(1), 72-81.

Kamarullah, K. (2017). Pendidikan Matematika di Sekolah Kita. Al Khawarizmi: Jurnal Pendidikan dan Pembelajaran Matematika, 1(1), 21-32.

Kumalasari, F. Nusantara, T. \& Sa'dijah, C. (2016). Defragmenting Struktur Berpikir Siswa dalam Menyelesaikan Masalah Pertidaksamaan Eksponen. Jurnal Pendidikan: Teori, $\begin{array}{llll}\text { Penelitian, dan Pengembangan, 246-255. } & \text { 1(2), }\end{array}$ doi: http://dx.doi.org/10.17977/jp.v1i2.6129

Kusaeri, \& Aditomo, A. (2019). Pedagogical Beliefs about Critical Thinking among Indonesian Mathematics Pre-service Teachers. International Journal of Instruction, 12(1), 573-590. https://doi.org/10.29333/iji.2019.12137a 
Kusaeri, K., Hamdani, A. S. \& Suprananto, S. (2019). Student Readiness and Challenge in Completing Higher Order Thinking Skill Test Type for Mathematics. Infinity: Journal of Mathematics Education. 8(1), 75-86. doi: https://doi.org/10.22460/infinity.v8i1.p7586

Mahmudah, W. (2018). Analisis Kesalahan Siswa dalam Menyelesaikan Soal Matematika bertipe HOTS berdasarkan Analisis Newman. Unisda Journal of Mathematics and Computer Science (UJMC), 4(1), 49-56.

Santoso, I. A. (2017). Proses berpikir semu (pseudo) siswa MTs NW Karang Bata dalam menyelesaikan soal cerita bangun ruang kubus dan balok. Undergraduate thesis. Universitas Islam Negeri Mataram

Subanji. (2013a). Proses Berpikir Pseudo Siswa dalam Menyelesaikan Masalah Proporsi, JTEQIP, 4(2), 207--227.

Subanji. (2013b). Pembelajaran Matematika Kreatif dan Inovatif. Malang: UM Press

Sumaryanta., Priatna, N., \& Sugiman. (2019). Pemetaan Hasil Ujian Nasional Matematika. IDEAL MATHEDU: Indonesian Digital Journal of Mathematics and Education, 6(1), 543557.

Wibawa, K. A., Nusantara, T., Subanji, \& Parta, I. N. (2018). Defragmentasi Pengakifan Skema Mahasiswa untuk Memperbaiki terjadinya Berpikir Pesudo dalam Memecahkan Masalah Matematis. Jurnal Pendidikan Matematika, 2(2), 100-115, doi: http://dx.doi.org/10.31000/prima.v2i2.755.

Wibawa, K. A. (2016). Defragmenting Struktur Berpikir Pseudo dalam Memecabkan Masalah Matematika. Yogyakarta: Deepublish. 